\title{
Editorial
}

\section{Ser crítico hoy}

\section{DOI: http://dx.doi.org/10.18566/comunica.n4l.aOl}

Difícilmente nuestras escuelas de formación y nuestros espacios de encuentro dejan de afirmar, cada vez que pueden, que el trabajo cotidiano y los esfuerzos académicos que se implican buscan ser, y aseguran lo son, "críticos".

La muletilla incorporada se recita paradójicamente como un rezo. Es decir, como un dogma sobre el cual no cabe duda o reniego. La condición es punto de partida y desde allí lo que sigue lo confirma. De ese modo, el conocimiento puesto en juego se presume valioso e iluminador porque trasciende lo visto y registrado y da pistas para comprender que el objeto, situación o fenómeno enfocado, después de esa práctica, estará desnudo y aliviado de disfraces y trapalandas. Listo para que sin artilugios pueda describirse, comprenderse y hasta valorarse, sin riesgos de engaño.

Pero esa criticidad que acompaña a la academia, e incluso al trabajo profesional, y que abrazamos como una cuasirreligión, ¿no sufre alteraciones de tiempo y lugar, actores y corrientes?' ¿Está realmente claro qué es "ser críticos hoy"?

\section{I}

La palabra "crítica", la acción de discernir, deriva de la palabra criterio (el concepto, el mecanismo). Y con la misma raíz griega kri(n) (derivada del protoindoeuropeo ${ }^{*} \mathrm{krn}$-, que en latín ofrece palabras como secretum y discernĕre). Así, en su interés por discernir la verdad, propone evitar la falacia o el error (ensayo y error).

Pero también el término crítica se vincula con crisis, por cuanto comparten la raíz, y la crisis denota ruptura. Así que la crítica, de alguna manera, también lo es, toda vez que busca lo que está por debajo de la superficie. Por debajo de lo que se presenta en primera instancia de determinado modo, y por ello rompe la exposición de lo que ofrece la base superior.

Así planteado, para pensar críticamente se requiere del soporte lógico y racional de nuestros pensamientos a través de un movimiento dialéctico que rete constantemente nuestra forma de pensar. Por ello, podemos considerar el pensamiento crítico como una actividad mental disciplinada
Comunicación

número 41

Julio - diciembre

2019 | pp. 5-9

\section{Gustavo Cimadevilla}

Presidente de la Asociación Latinoamericana de Investigadores de la Comunicación, ALAIC (2018-2020). Director del doctorado en Ciencias Sociales de la Facultad de Ciencias Humanas, Universidad Nacional de Río Cuarto, Argentina.

gcimadevilla@yahoo.com.ar

1 En este escrito, se da por supuesto gnoseológico que el pensamiento crítico no depende del cultivo de una corriente teórica en particular, sino del tipo de ejercicio intelectual que se siga. De ese modo, no se estima que se es crítico por "naturaleza" por adherir a una posición francfurtiana, ni que no se es cuando se sigue el interaccionismo simbólico. Sino, en todo caso, que es el tipo de ejercicio intelectual que se lleva a cabo el que permite avanzar o no con esa condición y asumiendo las características que en este trabajo se destacan. 
que permite evaluar los argumentos o proposiciones haciendo juicios que puedan guiar tanto la duda como la toma de decisiones. Aquí la dialéctica aporta su modo de conjugar los contrarios, para comprender que no son las linealidades las que abundan en las formas de acontecer lo real, sino, en todo caso, las múltiples posibilidades y opacidades en las que arraigan los devenires. Incluyendo las oposiciones, las ambigüedades, las reciprocidades y los contrarios. De acuerdo con lo que tan operativamente Gurvitch (1982) propusiera.

\section{II}

Pero entonces también cabe preguntarse cuándo el pensamiento es no crítico. La respuesta puede parecer simple, aunque merezca ser revisada: cuando es puramente emocional, intuitivo sin dudas, prejuicioso sin más, o habitual o rutinario, sin el tamiz de las razones.

De ese modo, "no se es crítico" cuando se elude el paso de discernir, separar, distinguir, asociar, implicar, analizar (en definitiva) mediante un juicio que invite a sumar interrogantes y otras operaciones que pongan bajo luces múltiples modos de ver el objeto, situación o fenómeno que interesa.

En ese marco, el pensamiento deja de ser crítico cuando se vuelve cerrado en sí mismo, cuando ya cree que posee una verdad absoluta y, por tanto, su ser acrítico obvia otras revisiones. Su completitud lo traiciona y su verdad revelada desconoce que en su entorno caben otras dudas. La clausura, entonces, opera paradójicamente: se toma como verdad crítica que no permite cuestionamientos.

\section{III}

¿Significa esto, por ejemplo, que las convicciones se llevan mal con la crítica? Si es que una convicción es un conjunto de principios a los que adherimos y tomamos por ciertos o valederos y referentes para una valoración, el problema no está en incorporarlos y defenderlos, sino en no reparar que su sentido, vigencia y trascendencia merecen ser comprendidos en torno a contextos y problemas de conocimiento específicos. Es decir, implicados en coordenadas en las cuales los objetos, situaciones y fenómenos admiten y adquieren determinadas significaciones que, dadas las posibilidades del devenir, deben también incluir la posibilidad de que nuevas lecturas sean hechas para comprender como válidas y pertinentes las convicciones asumidas en un caso y en otro.

La convicción, entonces, también requiere de reflexión. 
Dewey ([1909] citado por Fisher, 2001), hace ya más de un siglo, al referirse al pensamiento reflexivo, nos dice que este libera de la actividad meramente impulsiva y puramente rutinaria; permite dilucidar entre lo puramente afectivo, ciego e impulsivo y la acción inteligente; y permite identificar consecuencias por adelantado.

En este sentido, el pensamiento reflexivo permite la formación de individuos más autónomos, con capacidad para entender la realidad a través de explicaciones, argumentaciones e interpretaciones de los contextos por sus propios medios. Y siempre atentos a sumar otras dudas e inquietudes que de manera continua y alerta adviertan hasta qué punto el conocimiento dado por válido merece ser sostenido.

\section{IV}

En ese marco, para Sternberg (1986) el pensamiento crítico incluye los procesos, estrategias y representaciones mentales que la gente usa para resolver problemas, tomar decisiones y aprender nuevos conceptos a través de sus propias capacidades. Y ello se realiza cotidianamente.

Así, el pensador crítico "ideal" es habitualmente inquisitivo, está bien informado, confía en la razón que interroga y asocia, tiene la mente abierta, es flexible, equilibrado en la evaluación, honesto al enfrentar sus sesgos personales, prudente al hacer juicios y está dispuesto a reconsiderarlos.

La American Philosophical Association (1990), por ejemplo, recuerda que para asuntos debatibles y complejos, ser ordenado y meticuloso en la búsqueda de información y en la selección de criterios es indispensable. Luego vendrá el análisis y la posibilidad de ofrecer operaciones que sumergidas en la complejidad no se apresuren ni deleiten por las conclusiones rápidas o los juicios pomposos. No son las frases exitistas las exitosas, sino, en todo caso, aquellas que por prudentes y comprometidas con la búsqueda de verdad se asoman para abrir pistas y mostrar senderos.

\section{V}

¿Respondemos nosotros al perfil de sujeto crítico que se desprende de estas caracterizaciones? Esta escritura pone el eje en la actitud de no aceptar las intuiciones desaprensivas, las creencias banales o las "verdades" a priori, sino solo después de haberlas hecho pasar por un conjunto de filtros que, independientemente de denominarse críticos, ayuden a discernir, pausar y revisar. Y para eso necesitamos ser "activos". 
El significado de "activo" en la definición de Dewey, nos recuerda León (2014), implica que no se trata de recibir ideas, almacenarlas, recuperarlas y comunicarlas como en un "tome y pase", sino de tamizarlas en un proceso en el cual cada uno piensa por sí mismo, formula preguntas, encuentra y asocia información relevante y llega a conclusiones propias, concienzudas y meritorias. Así que lo "persistente" y "cuidadoso" se opone a lo "perezoso", "automático" e "impulsivo", menciona el autor. Y es que no es cuestión de saltar a conclusiones fáciles y veloces, sino de realizar los juicios y las evaluaciones necesarias, más allá del tiempo que puedan requerir. A decir de Dewey (citado por León, 2014, p. 4), “la clave está en la calidad de las razones para creer en algo y en la conciencia de las implicancias que pueden tener esas creencias", toda vez que se comuniquen y puedan ser consideradas por su vinculación a la verdad.

Esta perspectiva fue enriquecida tres décadas después, cuando Edward Glaser ([1941] citado por Fisher, 2001) definió el pensamiento crítico como i) una actitud de estar dispuesto a considerar de manera pensante los problemas y asuntos que caen en el rango de nuestra experiencia; ii) un conocimiento de los métodos de la inquisición y el razonamiento lógicos; y iii) cierta habilidad en la aplicación de estos métodos.

\section{V $\mathbf{T}$}

El pensamiento crítico requiere, entonces, de un esfuerzo persistente para examinar cualquier creencia o forma de conocimiento a la luz de la evidencia que lo apoya, las operaciones lógicas que lo habilitan y las conclusiones consiguientes a las que tiende.

En este marco, un conjunto de principios para que el trabajo intelectual honre el esfuerzo y la actitud crítica resultan convenientes. Así:

\section{a. Una crítica no puede ser ingenua, sino dubitativa}

Cualquier observación, juicio o creencia merece que ciertas preguntas sean hechas para ayudar a comprender y dimensionar mejor aquello que se trata. La ingenuidad da por cierto o acabado un juicio o proposición, y, por tanto, naturaliza. La inquietud por la interrogación, en cambio, abre, desvela e ilumina zonas que requieren dilucidación.

\section{b. No puede ser lineal, sino "vericueta"}

Las inquietudes que asocian puntos deben transitar más allá de lo que resulta evidente. No es lo aparente lo que agota nuestra capacidad de interrogar, sino, por el contrario, solo un punto de partida sobre el cual deben luego tejerse puentes para descubrir los múltiples lazos y nudos que conforman nuestro objeto de interrogación. 


\section{c. No puede ser focal, sino integrativa}

El ejercicio crítico no puede tan solo aislar ciertos componentes. Después de asociar e interconectar objetos y fenómenos, debe sumar a los interrogantes iniciales otras inquietudes que devengan de campos conexos. Ninguna disciplina agota el conjunto de preguntas y observaciones posibles. Es en el trabajo articulado de los campos donde mejor cuenta puede darse de la realidad que importa.

\section{d. No puede ser autonominativa, sino pura consecuencia}

No es nuestro ejercicio intelectual el que bautiza el tipo de conocimiento que construimos. El carácter crítico de un trabajo deviene de su tratamiento y propuesta inquisidora. Lo "crítico" surge del propio lector, quien en su visitar intelectual encuentra en el texto de referencia una luz que lo ayuda a comprender y a hacerse nuevas preguntas.

\section{e. No puede cerrar, sino abrir}

Finalmente, diremos que todo trabajo crítico abre, antes que cerrar. Abre a nuevas preguntas y horizontes de indagación. Abre con sus conclusiones a la renovación del pensamiento que sobre determinado tema o problema existe. Ayuda a desnaturalizar y a profundizar en las raíces en las que se cierne la realidad tratada.

Es con el pensamiento crítico y la crítica del pensamiento que se cultivan la autonomía, la libertad de criterio y la incesante búsqueda de conocimiento, sin más fronteras que las impuestas por las propias capacidades con las que pretendemos comprender el mundo que recibimos, cohabitamos y configuramos.

\section{Referencias}

American Philosophical Association. (1990). Critical thinking: A statement of expert consensus for purposes of educational assessment and instruction. Educational Resources Information Center (ERIC), Departamento de Educación de los Estados Unidos.

Fisher, A. (2001). Critical thinking: An introduction. Cambridge

University Press.

Gurvitch, G. (1982) [1962]. Dialéctica y sociología. Dom Quixote.

León, F. (2014). Sobre el pensamiento reflexivo, también llamado pensamiento crítico.

Propósitos y Representaciones, 2 (1), 161-214. doi: http://dx.doi.org/10.20511/ pyr2014. v2n1.56

Sternberg, R. (1986). Critical thinking: Its nature, measurement, and improvement. Educational Resources Information Center (ERIC), Departamento de Educación de los Estados Unidos. 